\title{
EL ROL DE LA FAMÍLIA EN LA LITERATURA INFANTIL I JUVENIL DEL SEGLE XXI: EL DESENVOLUPAMENT DE LA COMPETÈNCIA LECTORA INTERCULTURAL A TRAVÉS D’UN ÀLBUM IL·LUSTRAT Rocío Domene Benito Universitat de València
}

Llegar a la emoción, al niño real, al niño que no es «de libro», que es global, diverso, que tiene ideas, capacidades, emociones, que tiene deseos de comunicar y de que lo escuchen y que debe aprender a escuchar, a respetar, a compartir, a buscar respuestas, a construir conocimientos, a vivir como un ser autónomo en una sociedad plural.

Anna Hervás, Emociones, acciones, conocimientos

\section{INTRODUCCIÓ}

7 radicionalment, la família ha estat un dels temes més adreçats als xiquets juntament amb d'altres com l'amistat o la natura. En aquest sentit, el principal objectiu d'aquest treball
d'investigació consistirà a fer un recorregut històric al voltant natura. En aquest sentit, el principal objectiu d'aquest treball
d'investigació consistirà a fer un recorregut històric al voltant observar com ha evolucionat i els canvis que s'han produit per a mostrarne la importància i diversitat. A més a més, ens centrarem en una anàlisi profunda del terme família i com en l'actualitat, subjecta a diferents variants psicològiques, socials, econòmiques i culturals, s'han configurat diversos models familiars, alguns dels quals s'allunyen del paradigma més convencional. Per tant, en una societat impregnada per un halo intercultural imperant, la família entesa com un concepte universal i flexible és considerada com un pilar bàsic en l'educació dels xiquets com a éssers humans.

En aquest sentit, amb la finalitat d'exemplificar de la manera més clara possible aquesta evolució, utilitzarem exemples d'albums illustrats que mostren diverses concepcions del terme família, des de la considerada com a família tradicional i nuclear fins a les noves famílies sorgides més recentment a causa de canvis en l'estructura social del món actual. Serà en les denominades noves famílies on ens centrarem principalment, 
mitjançant l'anàlisi de l'àlbum il.lustrat In Our Mothers' House (2009) de l'escriptora nord-americana Patricia Polacco. A través de la història d'una família allunyada dels cànons tradicionals (conformada per dues mares $i$ tres fills adoptats provinents de diferents ètnies $\mathrm{i}$ cultures), explorarem com tracta Polacco el tema de la família atenent al gran valor que adquireix en la formació dels alumnes com a éssers humans. També, la riquesa d'aquest llibre resideix en el predomini de la interculturalitat, és a dir, en el diàleg i la interacció (ABDALLAH-PRETCEILLE: 2001) que s'estableix entre les diferents cultures. Per tant, In Our Mothers' House representa una eina eficaç i útil per a mostrar als estudiants que no existeix un únic concepte de família i, així mateix, la rellevància de la interculturalitat al món que els envolta.

També, a banda de la interculturalitat i la família, un altre dels eixos transversals en què es fonamenta aquest estudi és la competència literària en el segle XXI (AGUADO: 2003; BALLESTER: 2007). És a dir, anar més enllà d'un simple desxiframent de signes, llegir entre línies, conversar amb les diferents cultures, respectar els altres, indagar en els missatges que ens transmeten els llibres per a convidar els alumnes a pensar d'una manera critica i reflexiva, i fomentar la seua imaginació i creativitat.

En conclusió, mitjançant un àlbum il.lustrat els professors podem afavorir el desenvolupament del xiquet, no sols en àrees lingüístiques, literàries i cognitives, sinó també morals i cíviques.

2. El PROBlema de la DELIMitació CONCEPTUAL DEL TERME FAMÍLIA I LA SEUA IMPORTÀNCIA EN EL DESENVOLUPAMENT DEL XIQUET COM A ÉSSER HUMÀ

En ple segle XXI, malgrat que podem trobar opinions i percepcions contraposades, investigadors i educadors coincideixen en la necessitat de revisar el terme familia amb l'objectiu d'ampliar-ne els seus límits, que s'han advertit obsolets. Ja el 1992, amb motiu de la celebració de l'Any Internacional de la Família, UNICEF assenyala que: «Muchos de los estereotipos o convenciones utilizados para describir la vida familiar se han quedado anacrónicos y no se sustentan ya desde un punto de vista real» (1992). En aquesta mateixa línia de pensament, trobem noves denominacions com pot ser la que empra Cicerchia (1994), que prefereix 


\section{Revista de Filologia}

parlar de formes familiars en què tots els nous models de família estiguen valorats $\mathrm{i}$ reconeguts per una societat plural i intercultural. També, la psicòloga i professora universitària argentina Eva Giberti analitza el canvi de gènere de la concepció familiar i substitueix l'article la per lo:

parecería prudente empezar a hablar de lo familiar como una alternativa que permita neutralizar el mensaje monádico, único, hegemónico que prescribe el artículo la, indicativo de un modelo incanjeable, cristalizado, inamovible, intolerante (GIBERTI: 1994, 118-120).

Tal com hem expressat anteriorment, cal desmitificar i trencar els estereotips socials i culturals sobre l'existència d'un únic i vàlid concepte de família. Així, doncs, aquesta reflexió es pot extrapolar a la literatura infantil $\mathrm{i}$ juvenil, en la qual als darrers anys ha augmentat la presència visible i amb veu pròpia de famílies monoparentals, homosexuals o no lligades per llaços de sang, entre d'altres. Orlando Rodríguez explica aquest fenomen que observa al continent americà així:

El reflejo literario creciente de esas circunstancias, que en mayor o menor medida comparten el resto de los continentes, no debe verse entonces como una actitud escéptica, o como una búsqueda de sensacionalismo o una moda, sino como un ejercicio de aproximación a la cotidianidad infantil y juvenil (RODRÍGUEZ: 1997).

Dit d'una altra manera, per què no treballar la quotidianitat del segle XXI? Per què no apropar la família als xiquets amb tot el seu simbolisme, amb tota la seua essència, vitalitat i actualitat? En paraules de Martine Segalen (1992), com una «institució viva, resistent i en transformació».

3. RECORREGUT HISTÒRIC: TRACTAMENT I PERSPECTIVA DE LA FAMÍLIA A TRAVÉS DE LA LITERATURA INFANTIL I JUVENIL

A continuació, farem un recorregut històric al voltant de la presència de la família en la literatura infantil i juvenil des dels seus inicis. Com hem indicat a la introducció, podem afirmar que és un dels temes favorits per a escriptors, editors i investigadors. 
En la vessant investigadora, cal destacar-hi l'obra The Family in English Children's Literature d'Ann Alston. En aquest monogràfic, l'autora britànica examina de forma exhaustiva el paper de la família en la literatura infantil i juvenil anglesa en el segle XIX i XX. Organitzat en dues parts, en la primera en detalla el sorgiment de la família nuclear vinculada a l'auge de la classe mitjana; així mateix, relata algunes descripcions de la família en la ficció infantil des de 1818 fins a 2003. Encara que analitza molts tipus de famílies, deixa veure que la família nuclear tradicional és, encara hui, el prototipus millor valorat, és a dir, els ideals d'aquest model es mostren intrínsecs en els exemples plantejats. Alston arriba a aquesta conclusió:

At the beginning of the twenty-first century, when families and their structures have changed considerably in society we might expect the traditional signifiers of the good family to have become redundant. But as this book has shown, these tropes retain their importance and those families that do not fulfil the ideal are invariably constructed as 'other' to the desirable norm (ALSTON: 2008, 135).

Pel que fa al terme l'altre, la interculturalitat i la diversitat hi juguen un paper fonamental i és ací on s'emfasitza la globalitat i la pluralitat de la família. Famílies nuclears (pare, mare, fill i filla), famílies extenses (pare, mare, fil, filla, àvia, avi...), famílies monoparentals (pare i fill, mare i fill, pare i filla...), famílies homosexuals (dues mares, dos pares i fills) i, tot això, influit per processos com divorcis o adopcions i intercanvis interculturals entre distintes ètnies, religions, etc.

Tornant a l'estructura organitzativa de llibre d'Alston, el punt següent tracta d'alguns aspectes clau en qualsevol família, com ara els espais domèstics o el menjar. En definitiva, l'autora ens transmet la importància de la família al llarg de la història de la literatura infantil i juvenil en llengua anglesa i destaca que, malgrat les diferències, prevalen les similituds i l'amor com a eix d'imbricació familiar.

D'altra banda, analitzarem tot seguit alguns exemples d'àlbums il.lustrats que reflecteixen les anomenades formes familiars. En primer lloc, allò que entenen com a familiar nuclear, representat per un pare i una mare amb els seus fills pot tindre diversos matisos. Cal recalcar això, ara més que mai, amb la irrupció de la interculturalitat i les famílies interra- 
cials com, per exemple, a l'àlbum il.lustrat How my parents learned to eat (1987) d'Ina R. Friedman, obra en què un fill conta com la seua mare japonesa i el seu pare americà es van enamorar, i celebra la diversitat cultural a través del menjar.

En segon lloc, convé ressaltar la rellevància dels avis en l'educació dels fills en les conegudes com a famílies extenses. Podem citar Grandfather counts (2003) d'Andrea Young, que narra la relació intercultural i intergeneracional que s'estableix entre un avi i una néta. En tercer lloc, la família homoparental és tractada d'una manera tendra en And Tango makes three (2005) de Justin Richardson i Peter Parnell. En aquesta història dos pingüins mascles ajudats per un treballador del zoo en què viuen aconsegueixen tindre un fill i formar una família. En quart lloc, el divorci es mostra en Fred Stays with me! (2011) de Nancy Cofflet, quan un gos es converteix en el principal salvador d'una xiqueta després del divorci dels seus progenitors. En darrer lloc, l'adopció ha esdevingut com una acció quotidiana en la vida dels xiquets com es veu en A Mother for Choco (1996) de Keiko Kasza. Aquest àlbum illustrat narra la historia de Choco, un ocell adoptat per una mare óssa.

Com es pot observar a través d'aquesta petita selecció, la interculturalitat s'adverteix com una norma, més que com una excepció (AGUADO: 2003). Així mateix, la literatura i la interculturalitat afavoreixen el desenvolupament d'una competència lectora intercultural entre els xiquets.

4. LiTERATURA INFANTIL I JUVENIL, INTERCULTURALITAT: DESENVOLUPAMENT DE LA COMPETÈNCIA LECTORA INTERCULTURAL DES D'EDATS PRIMERENQUES

Per acabar el marc teòric, analitzat el desenvolupament de la família des d'una perspectiva cultural, social i literària, ens ocuparem de com aprofitar aquest món tan divers i ric a través de la lectura. Aguado defineix les competències interculturals com «las habilidades cognitivas, afectivas y prácticas necesarias para desenvolverse eficazmente en un medio intercultural» $(2003,141)$; és a dir, aquells coneixements, procediments i 
principis que l'alumnat desenvolupa amb l'ajuda de l'equip docent per comprendre i enriquir-se del món que l'envolta, del seu jo i de l'altre.

En relació amb aquestes competències, sorgeix la necessitat d'un enfocament literari com el que proposa Ballester (2007), que advoca per una competència literària en què els estudiants penetren el text $\mathrm{i}$ cerquen la verdadera realitat de les paraules, la seua essència real, el seu significat més enllà de la lectura passiva de signes (BALLESTER: 2007, 117). Per tant, una lectura activa es fa indispensable i afavoreix que cobre especial protagonisme el foment de la imaginació i el pensament crític.

En resum, l'ús de la literatura afavoreix l'enriquiment del xiquet tan acadèmicament com emocionalment i aporta molts beneficis (COLLIE $\&$ SLATER: 1990; LAZAR: 1993; PARKINSON \& THOMAS: 2000), com ara el desenvolupament íntegre del xiquet com a ésser humà des d'un punt de vista cultural, element pel qual els xiquets prenen consciència de la diversitat del món i de l'existència d'altres cultures i, en aquest cas, de la riquesa familiar.

\section{ANÀlisi DE L’ÀlBUM IL-LUSTRAT IN OUR MOTHERS' HOUSE}

En seccions prèvies hem observat els diferents models de famílies presents en la literatura infantil i juvenil $i$, tot seguit, analitzarem amb detall l'àlbum il.lustrat In Our Mothers' House, escrit per Patricia Polacco, i que té com a tema central la família homoparental. A través d'un llenguatge directe, poètic i senzill i unes illustracions farcides de tendresa i color, l'autora nord-americana conta la història d'una família conformada per dues mares que decideixen adoptar tres fills de diferents ètnies $i$ nacionalitats amb l'objectiu de fer realitat el seu somni de formar una família, de formar una llar en què l'amor siga el centre de les relacions que s'estableixen entre tots els membres de la família.

Quant a l'estructura i punt de vista narratiu, la filla major és l'encarregada de contar la història de la seua família des del seu naixement. Com es construeix una família? Existeix una construcció més vàlida que una altra? Es coneix des del principi que aquesta no conté els mateixos llaços de sang però l'amor, l'enteniment i el respecte mutu apareix ja a les primeres línies: «They told me how they walked across dry hot deserts, sailed through turbulent seas, flew over tall mountains and trek- 
ked through fierce storms just to bring me home» $(2009,1)$. Les descripcions estan també presents quan relata l'arribada dels altres germans i les seues mares: «Ours mothers loved to laugh» $(2009,7)$. Continua amb la descripció de la casa on viuen, una casa que cobra vida i pot ser considerada un altre personatge; de fet, com un dels més importants perquè és on es desenvolupen la majoria de les activitats de la família. La xiqueta descriu amb emoció diverses situacions com quan es disfressen en la habitació dels joguets o la felicitat que irradien els xiquets i els adults en el jardí mentre construeixen una casa en un arbre, tot junts i en harmonia.

A mesura que avança l'acció, nous personatges apareixen com, per exemple, Miso i Wasabi, dos gossos que completen la família. En aquest punt, cal ressaltar la importància dels animals com a membres del cercle familiar, sobretot per als més menuts. Una altra situació que mereix una menció especial és el paper que juguen els avis en la vida dels seus néts i nétes. En aquesta família, la interculturalitat es troba reflectida quan arriben els avis italians i s'estableix un diàleg culinari d'intercanvi de receptes: «Our Italian grampa, our nonno, was in charge of cooking. We loved gnocchil» $(2008,20)$. A més a més, de nou la casa, més concretament, la cuina, és l'espai on tenen lloc aquestes experiències vitals plenes d'amor i tendresa. El relat continua amb una celebració del Nadal amb tota la família reunida: «It was the best part of the day. Marmee and Meema would listen in and smile» $(2009,24)$.

Però, desafortunadament, no tot és meravellós a la vida real i inclús els xiquets han de viure situacions desagradables. El personatge antagònic és una veïna que no accepta la família formada per Marmee and Meema:

Why doesn't that lady like us, Meema? I asked my mother.

She just smiled at me and hugged me up. I like you, baby, she said (POLACCO: 2009, 26).

$[\ldots]$

What's the matter with her, Momma, what's the mater with her? Millie kept saying.

All the neighbors closed in on us.

She is full of fear, sweetie. She's afraid of what she cannot understand: she doesn't understand us, Meema quietly said.

There seems to be no love in her heart, either, whispered Marmee (POLACCO: 2009, 31). 
Com podem comprovar, es tracta d'una dona que no accepta la diversitat cultural i les noves formes familiars que, fins i tot, es basen en les mateixes concepcions que la anomenada com a tradicional: l'amor i la protecció. Així ho expressa la filla: «There wasn't a day in my life that I didn't feel deeply loved and wanted by Meema and Marmee» (2009, 33).

A banda de la família, un dels temes que es poden observar en aquest àlbum il.lustrat és el cicle de la vida; en altres paraules: el creixement personal d'una xiqueta des de la seua infantesa fins a la seua edat adulta. Els germans es casen i abandonen la casa de les mares, però només és un abandonament físic, ja que les vivències viscudes a la casa romandran intactes als seus cors per sempre.

$\mathrm{Al}$ desenllaç, la primogènita narra la volta als orígens: «They fell into the waiting arms of their grandmothers. Just as we had done» (2009, 39). Ara són els néts els que gaudeixen de l'amor de les àvies. Finalment, com tot cicle vital, la mort és l'últim pas, les àvies ja no hi són físicament, però la casa, les habitacions, les disfresses, els jocs, la cuina i tot el que havien viscut amb elles es quedarà en les parets d'una de les parts més importants de la seua vida: «All of our hearts find peace whenever we are there... not only remembering them, but being there, together, in our mothers' house» $(2009,44)$.

Un altre aspecte rellevant en tot llibre per a infants $i$ joves és la relació que s'estableix entre la paraula i la imatge. En aquest sentit, les il.lustracions acompanyen el text d'una manera magistral. Podríem destacar les imatges on hi ha la família unida, per exemple, a la cuina (2009, 21-22) o al Nadal (2009, 23-24), o l'última imatge, en què es mesclen els colors foscos que simbolitzen la nit i la mort de les àvies i les llums dels néts que les recorden mentre miren cap a les estreles (2009, 43-44).

En conclusió, a través de la història d'una família homoparental formada per dues mares i tres fills adoptats, provinents de diferents ètnies i cultures, Patricia Polacco explora temes que podem considerar com a controvertits per als xiquets, com són les famílies amb progenitors del mateix sexe o la mort, però també d'altres de més tradicionals com la importància de les mascotes i els avis a la infantesa. Recapitulant, l'autora aconsegueix en unes poques pàgines confegir una història completa amb 
molts matisos, una invitació a la reflexió. Aleshores, com es construeix una família? Existeix un procés de construcció més vàlid que un altre?

\section{CONCLUSIÓ}

$\mathrm{Al}$ voltant de les dues últimes preguntes formulades en l'apartat anterior, podem concloure amb la idea que no existeix una definició única del terme «família». Tanmateix, la societat actual ha de conéixer i valorar d'una manera equitativa tots els conjunts de persones que comparteixen una llar on l'amor i el respecte són els elements bàsics de coexistència.

Tal com hem discernit al llarg d'aquest treball, la família és un dels temes més emprats en la literatura infantil i juvenil en la majoria de cultures del món. No obstant això, cal revisar-ne el concepte i mostrar-lo amb les seues connotacions actuals als àlbums illustrats. Això és el que preteníem a través de l'anàlisi minuciosa d'In Our Mothers' House, plasmar com són les famílies reals, les famílies dels xiquets que acudeixen cada dia a escola. És clar que tots els xiquets han de sentir-se protagonistes de la seua educació $i$ veure les seus experiències $i$ vivències als textos $i$ il.lustracions dels llibres infantils. De manera paral.lela, al mateix temps, ells desenvolupen una competència lectora i literària intercultural, que els permet fomentar la imaginació i el pensament crític. És a dir, mitjançant la lectura comprensiva i activa de la història de Patricia Polacco, els estudiants es pregunten els motius dels esdeveniments, analitzen d'una manera crítica les situacions menys agradables i intenten proposar solucions.

En definitiva, a través d'un tema tan explotat i antic, però alhora tan viu i emergent en els nostres dies, com a reflexió sobre la família, pensem que els docents, educadors i tota la comunitat educativa poden utilitzar la literatura com una eina eficaç amb l'objectiu de promoure la competència lectora intercultural, que afavoreix no sols l'aprenentatge i l'ensenyament de continguts purament acadèmics, sinó també de continguts morals i cívics.

BIBLIOGRAFIA

ABDAllah-PRETCEILLE, Martine (2001): La educación intercultural, Barcelona, Idea Books.

AguAdo, Teresa (2003): Pedagogía Intercultural, Madrid, McGraw Hill. 
Alston, Anne (2008): The Family in English children's literature, Nova York, Routledge.

BAllester, Josep (1999 [2007]): L'educació literària, València, Publicacions de la Universitat de València.

CHENG, Andrea \& Ange ZHANG (2000): Grandfather counts, Nova York, Lee \& Low Books.

CiCERCHIA, Ricardo (1994): Familias y ciencias sociales. El encanto de las formas familiares, UNICEF, Argentina.

COffelt, Nancy \& Tricia TuSA (2007): Fred stays with me, Nova York, Little, Brown Books for Young Readers.

FRIEDMAN, Ina R. \& Allen SAY (1984): How my parents learned to eat, Boston, Houghton Mifflin.

GiberTi, Eva (1994): «La familia y los modelos empíricos», en Catalina WAINEMAR (coord.), Vivir en Familia, Buenos Aires, UNICEFLosada.

HERVÁS, Anna (2008): «Emociones, acciones, conocimientos», en José A. TÉLlEZ, Educación intercultural. Miradas multidisciplinares, Madrid, Los Libros de la Catarata.

KASZA, Keizo (1992): A Mother for Choco, Nova York, Putnam.

ORLANDO, Antonio (1997): «Tratamiento de la familia en la literatura infantil y juvenil contemporánea», Lectura y Vida, núm. 3.

PolaCCO, Patricia (2009): In Our Mothers' House, Nova York, Philomel Books.

Richardson, Justin, Peter Parnell \& Henry Cole (2005): And Tango makes three, Nova York, Simon \& Schuster Books for Young Readers.

SEgALEN, Martine (1992): Antropología histórica de la familia, Madrid, Taurus. 